\title{
Alteridade e subjetividade social por intermédio da escrita espontânea no ciclo de alfabetização: relato de experiência no ensino fundamental
}

\author{
Thiago Reginaldo* \\ Maria Sirlene Pereira Schlickmann ** \\ Ademilde Silveira Sartori***
}

\section{Resumo}

Este artigo relata a experiência do estágio supervisionado no ciclo de alfabetização do curso de pedagogia da Universidade do Sul de Santa Catarina que ocorreu no Centro de Atenção Integral à Criança Prof. Febrônio Tancredo Oliveira, no município de Palhoça, SC. O objetivo do artigo é apresentar metodologicamente a escrita espontânea em uma turma de alfabetização como prática de trabalho da subjetividade social e da alteridade. A turma era formada por 23 alunos, que participaram das aulas entre agosto e outubro de 2015. Utilizaram-se as seguintes técnicas de coleta de dados: diário de estágio, observação participante, fotografias, vídeos e materiais produzidos durante o processo de observação e intervenção. Foi possível perceber que a escrita espontânea em uma concepção de pedagogia relacional com abordagem histórico-cultural no processo de alfa- betização é uma prática que se constitui também pela subjetividade social (REY, 1993, 1997) e alteridade como paradigma educativo (ROSA, 2012).

Palavras-chave: Alteridade. Subjetividade social. Alfabetização. Escrita espontânea. Ensino fundamental.
* Doutorando em Educação pelo Programa de Pós-Graduação em Educação da Universidade do Estado de Santa Catarina. E-mail: th.reginaldo@gmail.com

** Doutora em Ciências da Linguagem pela Universidade do Sul de Santa Catarina. Professora no curso de Pedagogia da Universidade do Sul de Santa Catarina. E-mail: sirlene.schlickmann@gmail.com

**** Doutora em Ciências da Comunicação pela Universidade de São Paulo. Pós-doutorada em Comunicação e Educação pela Universidade Complutense de Madri, Espanha. Professora no Centro de Ciências Humanas e da Educação da Universidade do Estado de Santa Catarina. E-mail: demildesartori@gmail.com

Data de submissão: mar. 2016 - Data de aceite: maio 2016 http://dx.doi.org/10.5335/rdes.v12i1.5862 


\section{Introdução}

Nos primeiros anos do ensino fundamental, o processo de ensino e de aprendizagem da escrita tem lugar de destaque na prática pedagógica, especialmente devido à complexidade desse processo, tanto por parte de quem ensina quanto de quem aprende. $\mathrm{O}$ ciclo de alfabetização, ${ }^{1}$ que compreende os três anos iniciais do ensino fundamental, é a fase em que trabalha-se o processo de ensino e de aprendizagem da alfabetização, de forma que $o$ aluno se aproprie do sistema de escrita alfabética e, gradativamente, torne-se letrado, ficando apto a ler o mundo (FREIRE, 1996), e consiga se comunicar e se expressar em variadas linguagens verbais e não verbais.

Assim, o quefazer dessa prática envolve uma estrutura complexa, composta por uma proposta pedagógica da escola, tempos e espaços escolares e professores alfabetizadores conscientes de sua intencionalidade pedagógica e com o domínio do fazer pedagógico, no que se refere ao processo de apropriação da leitura e da escrita pela criança no processo de alfabetização.

A formação do professor alfabetizador nesse processo exige, segundo Soares (2011), que ele aprenda as especificidades do processo de alfabetização, de forma que possa compreender todas as facetas (psicológica, psicolinguística, sociolinguística e linguística) e os condicionantes (sociais, culturais e políticos) envolvidos. Esse sujeito deverá saber operacionalizar todos esses aspectos em procedimentos e usos adequados de materiais, bem como assumir uma postura política diante das implicações ideológicas do significado e do papel atribuídos à alfabetização.

Ademais, a tarefa dos professores, de ensinar os alunos do $1^{\circ}$ ano a ler e escrever, torna-se ainda mais difícil ao se considerar a ampliação do ensino fundamental brasileiro para nove anos e a transição que decorre pela saída da educação infantil. De acordo com Goulart (2007), o planejamento do ensino para os alunos de seis anos deve prever essas diferenças e também atividades que alternem movimentos, tempos e espaços, de modo que a passagem da educação infantil para o ensino fundamental seja de continuidade dos processos de aprendizagem.

O espaço público da escola deve, portanto, oferecer aos alunos um ambiente em que a alfabetização esteja ligada a processos sociais de vivência, convivência e criatividade, respeitadas as singularidades infantis (KRAMER, 2007). O processo de apropriação da escrita estará nesse contexto aliado ao que Vigotski (2008) chama de linguagem escrita e seu papel fundamental no desenvolvimento cultural da criança. Dentro de algumas das suas implicações práticas, o autor irá relatar pontos importantes, dentre eles, que a escrita deve ter significado para as crianças e deve ser ensinada de modo natural, espontâneo, mas não espontaneísta. 
O professor é o mediador desse processo de significação de escrita pelos aprendizes e suas ações pedagógicas devem conduzir esse aprendizado de forma que as crianças se interessem pela apropriação da linguagem escrita. De acordo com Vigotski, “[...] uma necessidade intrínseca deve ser despertada nelas e a escrita deve ser incorporada a uma tarefa necessária e relevante para a vida" (2008, p. 144). Neste texto, nossa proposição e nossas discussões caminham nesse sentido, com base no uso da escrita espontânea, o que a nosso ver desloca a criança para uma condição de protagonista no processo de escrita.

A escrita espontânea é compreendida com base no conceito de Silva (1991), que afirma que as crianças têm condições de propor a sua própria ortografia para as palavras que desejam escrever, desde que o ambiente que vivam encoraje $o$ uso significativo da escrita, sem medo de errar, estimulando-a a refletir sobre os usos que pode fazer dela na sociedade. No entanto, seguindo o pensamento de Weisz (2006), deve-se ter cuidado para que esse conceito não caminhe em direção a uma onda de práticas pedagógicas espontaneístas. Portanto, o planejamento das situações de ensino e de aprendizagem deve acontecer de maneira a envolver esse conceito, que necessita ser pensado pelos professores em meio a outras diversas possibilidades pedagógicas de alfabetização, de modo a haver uma articulação entre elas. É o professor também protagonizando sua prática.
Nesse sentido, por se constituir uma prática que considera o repertório da criança e o contexto vivido, a escrita espontânea tem potencialidades de articular os alunos com o ambiente e, dessa forma, fomentar a subjetividade social e a alteridade. O objetivo deste artigo é apresentar, metodologicamente, a prática da escrita espontânea utilizada no estágio supervisionado no $1^{\mathrm{o}}$ ano do ciclo de alfabetização como possibilidade de trabalho da subjetividade social e da alteridade.

O artigo está organizado de modo que seja possível compreender os percursos metodológicos: o contexto da aula, a análise do processo de convivência na docência, a escrita espontânea com base no conceito de Silva (1991), a subjetividade social na perspectiva de Rey (1993, 1997), e a alteridade como paradigma educativo sob a luz de Lévinas (1998 apud ROSA, 2012).

\section{Percurso metodológico}

Este trabalho consiste em um relato de experiência do estágio supervisionado de pedagogia no ciclo de alfabetização, que apresentou trinta horas aula de carga horária presencial na escola, entre observações e intervenção. Essa disciplina é caracterizada pelas práticas de observação e registro do processo de ensinar e aprender na alfabetização, que envolve análise da documentação pedagógica, construção de projeto de estágio e planejamento, execução e avaliação 
de atividades pedagógicas a serem desenvolvidas na turma de alfabetização. Assim, para a realização do estágio de docência foi escolhida uma turma de $1^{\circ}$ ano do ensino fundamental, com 23 alunos com idades entre 6 e 7 anos.

O estágio ocorreu de agosto a outubro de 2015, no Centro de Atenção Integral à Criança Prof. Febrônio Tancredo Oliveira. O estágio é requisito obrigatório para conclusão do curso de Pedagogia da Universidade do Sul de Santa Catarina. Foram realizados três dias de observação, que ocorreram entre agosto e setembro, um dia de aproximação com os alunos e três dias de intervenção, no mês de outubro. A publicação desta pesquisa foi autorizada pela direção da escola.

O estudo que envolveu o estágio supervisionado tem caráter qualitativo e aborda a problemática a partir de métodos descritivos e observacionais. Foram utilizados os seguintes instrumentos para a coleta de dados: diário de estágio, observação participante, fotografias, vídeos e materiais produzidos durante o processo de observação e intervenção. Não foram utilizados dados pessoais dos alunos, apenas os momentos da prática pedagógica, que compõem o processo da aula e essa fase da sua formação.

A prática pedagógica foi conduzida pelo estagiário dentro do que Freire (2015) acredita ser indicotomizável: de uma ação (prática) se subentende uma teoria. Assim, as reflexões, os diálogos, o quefazer problematizador, o logos da realidade e as interações traduziram a intencionalidade pedagógica.

O diálogo e a problematização não adormecem a ninguém. Conscientizam. Na dialogicidade, na problematização, educador-educando e educando-educador vão ambos desenvolvendo uma postura crítica da qual resulta a percepção de que este conjunto de saber se encontra na interação. Saber que reflete o mundo e os homens, no mundo e com ele, explicando o mundo, mas sobretudo, tendo de justificar-se na sua transformação (FREIRE, 2015, p. 70).

Paulo Freire, ao fazer tal afirmação, refere-se à escola primária e ao professor. Isso traduz a pedagogia relacional que envolveu a prática de estágio: não havia um sujeito centro do processo, e sim uma centralidade dos sujeitos do processo que assumiam seus papéis de acordo com os objetivos das situações significativas e com as necessidades que iam surgindo. A seguir, será apresentado o que foi observado no estágio por meio da prática pedagógica da professora pedagoga com os seus alunos.

\section{Contexto da aula: entre registros e vivências}

No período de observação das aulas, foi possível verificar como a professora propõe as atividades para os alunos e convida o grupo para o aprendizado. Os alunos realizam atividades a partir do livro didático disponibilizado pela prefeitura, utilizam materiais didáticos disponíveis na sala de aula, o caderno de atividades, o caderno de deveres, a agenda para se comunicar com os pais, $\mathrm{e}$ 
fazem saídas em um determinado dia da semana para escolher uma obra literária na biblioteca. O currículo contempla todas as áreas de conhecimento previstas pela legislação pertinente e órgãos oficiais da educação, mais a disciplina de Informática.

Na rotina escolar dos alunos, há certa rotinização das atividades, dos tempos e dos espaços. As crianças cantaram, durante os dias de observação, a mesma música ao chegar à escola. A sala estava organizada do mesmo modo e as crianças saíram da sala de aula apenas para as aulas de educação física e de informática.
Ao tocar o sinal de início das aulas, as crianças formaram duas filas no pátio da escola, uma de meninos e outra de meninas, e esperaram a professora aparecer para buscá-las e encaminhá-las à sala de aula. Lá, as crianças cantaram a música Bom dia, como vai e depois uma música sobre os dias da semana. Posteriormente, as crianças leram os letreiros fixados em cima do quadro e uma série de sílabas (Figura 1). Depois da realização das atividades, elas formaram duas filas para irem ao recreio, na volta à sala, desenvolveram mais atividades.

Figura 1 - Professora realizando a leitura com os alunos

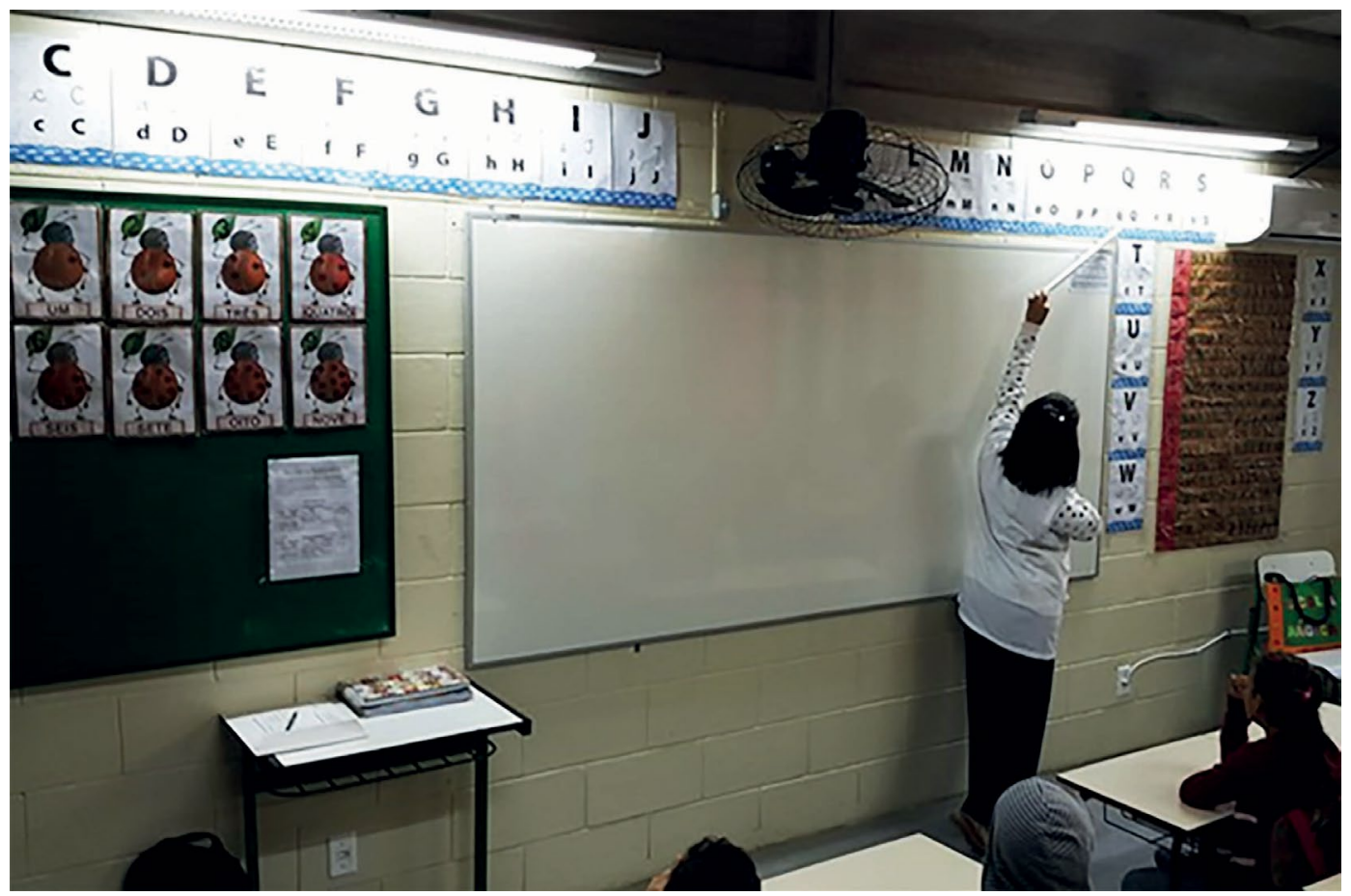

Fonte: foto elaborada para registro de estágio. 
As atividades que as crianças realizaram em sala de aula foram feitas no chamado caderno de atividades, compostas pelos assuntos discutidos em sala, que são escritos pela professora no quadro, e copiados pelos alunos no caderno, ou foram atividades em cartilhas (fotocópias), com cálculos, lacunas para completar com palavras, pontilhados para preencher, entre outras tarefas. Havia também o caderno de deveres, em que outras atividades eram passadas para as crianças fazer em casa. O caderno de caligrafia era utilizado para treinar a escrita cursiva. Além de todos esses cadernos, havia também a agenda, um instrumento importante no processo de comunicação entre pais/ escola/professora.

Em termos metodológicos, é possível perceber que o sistema utilizado pela docente é uma prática ancorada em uma perspectiva tradicional, em que há destaque para as práticas tradicionais de alfabetização, tais como: a cópia, a repetição, a memorização. De acordo com Orlandi (2011), a prática docente que se ancora nesses rituais institucionalizados, com práticas discursivas sedimentadas historicamente, pode ser definida também como discurso autoritário.

Entretanto, mesmo percebendo que a prática docente traz no seu bojo traços discursivos que denotam uma abordagem teórico-metodológica mais conservadora, os alunos desenhavam e escreviam de acordo com as atividades propostas, sempre individualmente. Eles podiam correr, pular e brincar no intervalo e nas aulas de educação física. Eram muito participativos e interessados em aprender. Conseguiam escrever e identificar seus próprios nomes e faziam a leitura das letras e sílabas que estavam coladas na parede, contudo, nem todos estavam no mesmo processo de aprendizado da escrita e da leitura.

A professora oferecia tempo para as crianças se expressarem oralmente, principalmente no começo das manhãs. Para as crianças que queriam falar, a professora deixava um momento em aberto para que apresentassem suas manifestações, porém, de maneira rápida e sem muita troca no diálogo. Ela escrevia no quadro com letra bastão (em caixa-alta) e, em caso de erros de escrita dos alunos, ela fazia com que as crianças apagassem e reescrevessem em seu caderno a forma correta. Atendia todos os alunos da mesma forma, o que reforça a observação da prática pedagógica ancorada no discurso autoritário, conforme mencionado anteriormente. A docente contava com um caderno de planejamento, no qual todas as atividades das crianças, durante a semana, estavam previamente planejadas, o que confirma que os sujeitos da aprendizagem do universo pesquisado são conduzidos por um processo planejado e mediado pela intencionalidade pedagógica. 


\section{Avaliação de escrita e leitura}

Pelas observações desenvolvidas na sala de aula em que o estágio foi realizado, percebeu-se o desenvolvimento de uma prática pedagógica que comtempla o trabalho individualizado dos alunos, ademais, havia alguns que ainda não haviam se apropriado do sistema de escrita alfabética. Alguns alunos copiavam rapidamente o que a professora escrevia no quadro, enquanto outros levavam muito tempo e, às vezes, só terminavam quando já era hora de ir embora, era uma turma bastante heterogênea.

Essa heterogeneidade discursiva (AUTHIER-REVUZ, 1990), que chama a atenção do professor no processo de ensino-aprendizagem, também é movida pela subjetividade, tanto docente quanto discente. E essa subjetividade dos sujeitos envolvidos no processo abre espaço para que possamos mobilizar também o conceito de alteridade, isso para que possamos compreender o modo como esses discursos articulam-se no processo de ensino e de aprendizagem da leitura e da escrita, especialmente nas manifestações dos aprendizes.

Nas Figuras 2 e 3, é possível observar exemplos da escrita de alunos. A maioria deles escreve com letra bastão e poucos com letra cursiva.
Figura 2 - Caderno de atividades com letra bastão

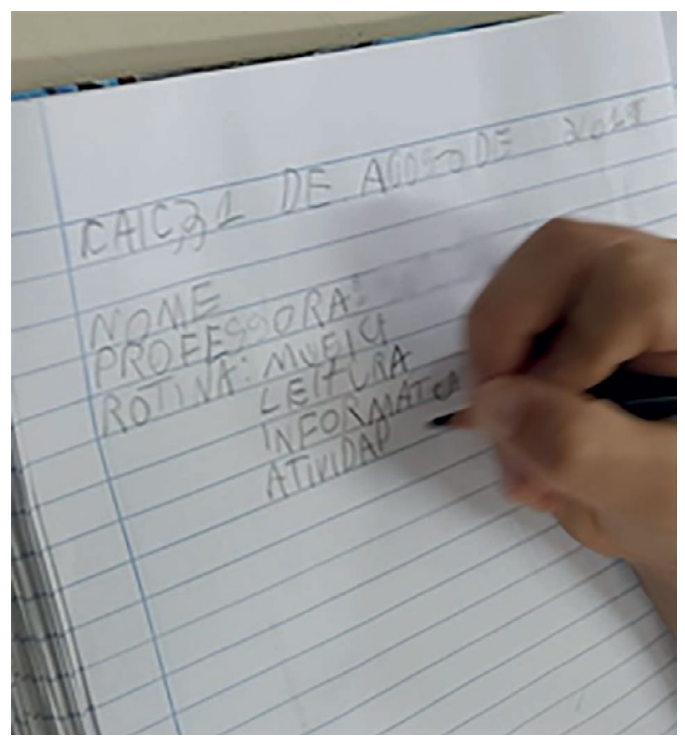

Fonte: foto elaborada para registro de estágio.

Figura 3 - Caderno de atividades com letra cursiva

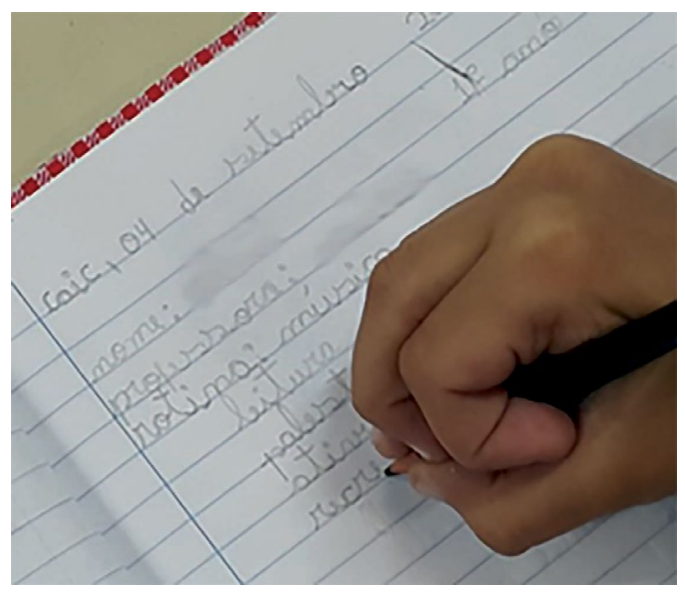

Fonte: foto elaborada para registro de estágio.

Para certificação do nível exato de escrita dos alunos, foi realizado, no último dia de observação, um diagnóstico de 
escrita e leitura, conforme sugerido por Moço (2009). Nele foi possível perceber que grande parte dos alunos encontra-se no nível silábico, três deles estão no nível pré-silábico, um no silábico-alfabético e quatro no alfabético² (Quadro 1).

Quadro 1 - Diagnóstico de escrita e leitura realizado pelo estagiário

\begin{tabular}{|c|c|c|c|c|c|c|c|c|c|c|}
\hline \multirow[t]{2}{*}{ Alunos } & \multicolumn{3}{|c|}{ Pré-silábico } & \multicolumn{4}{|c|}{ Silábico } & \multirow{2}{*}{$\begin{array}{c}\begin{array}{c}\text { Silábico- } \\
\text { alfabético }\end{array} \\
1\end{array}$} & \multicolumn{2}{|c|}{ Alfabético } \\
\hline & 1 & 2 & 3 & 1 & 2 & 3 & 4 & & 1 & 2 \\
\hline \multicolumn{11}{|c|}{ 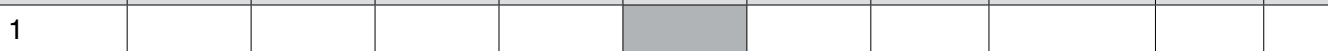 } \\
\hline \multicolumn{11}{|l|}{2} \\
\hline \multicolumn{11}{|l|}{3} \\
\hline \multicolumn{11}{|l|}{4} \\
\hline \multicolumn{11}{|l|}{5} \\
\hline \multicolumn{11}{|l|}{6} \\
\hline \multicolumn{11}{|l|}{7} \\
\hline \multicolumn{11}{|l|}{8} \\
\hline \multicolumn{11}{|l|}{9} \\
\hline \multicolumn{11}{|l|}{10} \\
\hline \multicolumn{11}{|l|}{11} \\
\hline \multicolumn{11}{|l|}{12} \\
\hline \multicolumn{11}{|l|}{13} \\
\hline \multicolumn{11}{|l|}{14} \\
\hline \multicolumn{11}{|l|}{15} \\
\hline \multicolumn{11}{|l|}{16} \\
\hline \multicolumn{11}{|l|}{17} \\
\hline \multicolumn{11}{|l|}{18} \\
\hline \multicolumn{11}{|l|}{19} \\
\hline \multicolumn{11}{|l|}{20} \\
\hline \multicolumn{11}{|l|}{21} \\
\hline \multicolumn{11}{|l|}{22} \\
\hline 23 & & & & & & & & & & \\
\hline
\end{tabular}

Fonte: modelo adaptado de Moço (2009).

Durante o diagnóstico, foram ditadas, primeiramente, palavras com mais sílabas até chegar-se às com menos sílabas, e, ao final, uma frase, por exemplo: PATINHO, URSO, SAPO e A MENINA TOMASOL. Foi possível perceber que algumas crianças compreendem as vogais, e outras já conseguem compreender as consoantes. Uma delas hesitou no momento de escrever e então olhou para o alto do quadro e copiou as letras iniciais do alfabeto $\mathrm{ABCD}$, que estavam coladas na parede. Na Figura 4, é possível observar alguns exemplos do diagnóstico e da escrita das palavras das crianças de acordo com o que foi ditado. 
Figura 4 - Diagnóstico da escrita

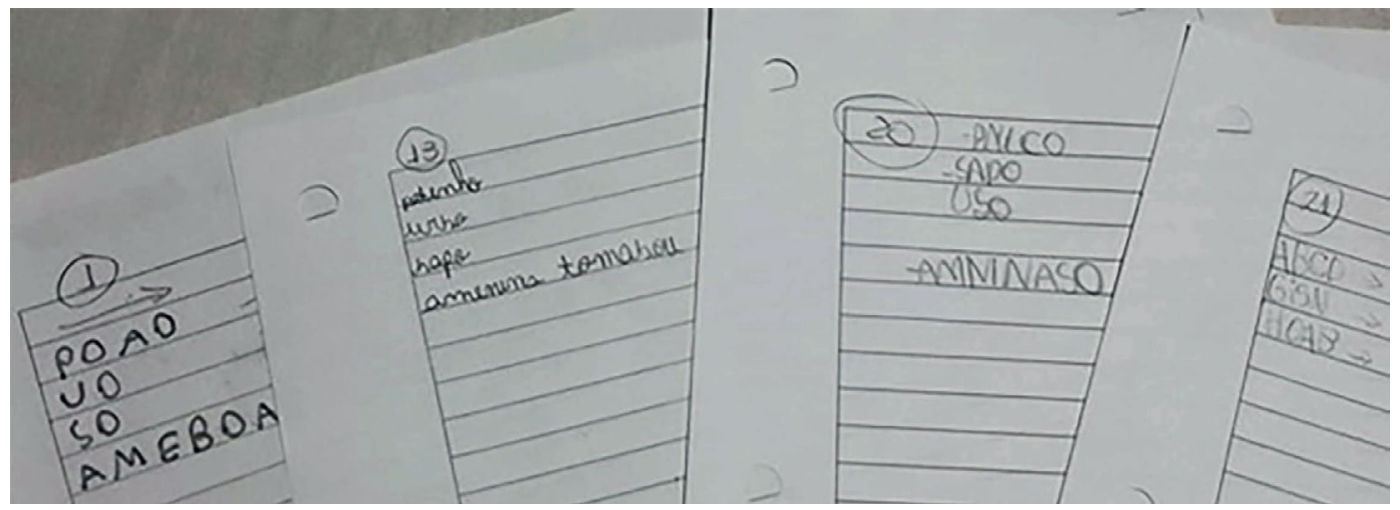

Fonte: foto elaborada para registro de estágio.

Pelo diagnóstico foi possível constatar que, apesar de todas as crianças copiarem o que a professora passa no quadro, três delas estavam no nível pré-silábico, o que significa a necessidade de uma atenção especial ao processo de aprendizado da escrita e leitura dessas crianças. Isso possibilita traçar correlações com a ideia de imitação da teoria de desenvolvimento e aprendizagem de Vigotskii:

Com o auxílio da imitação na atividade coletiva guiada pelos adultos, a criança pode fazer mais do que com sua capacidade de compreensão de modo independente. A diferença entre o nível das tarefas realizáveis com o auxílio de adultos e o nível das tarefas que podem desenvolver-se com uma atividade independente define a área de desenvolvimento potencial da criança (1988, p. 112).

Assim, com o auxílio da professora, as crianças já conseguiam copiar o que estava no quadro, no entanto, algumas delas ainda não conseguiam ler e escrever. $\mathrm{O}$ diagnóstico de leitura e escrita ajudou a situar a zona de desenvolvimento efetivo dos alunos e a pensar em formas de mediação na intervenção de estágio que possibilitassem $o$ aprendizado contextual carregado de sentido e significado. Esse processo de identificação da zona de desenvolvimento eminente dos alunos é também carregado de subjetividade, $o$ que exige por parte do docente um olhar cuidadoso sobre o processo do aprendiz, um olhar observador, que escuta/ouve, mas que também questiona, que dá a palavra para os aprendizes, desenvolvendo sua autonomia de forma a fortalecer a sua voz como sujeito autor e escritor. No entanto, esse é um processo que exige que todos que constituem esse lugar possam "compreender discursivamente a escola" (PFEIFFER, 2011, p. 231), o que nos desafia a considerar as subjetividades e alteridades das relações sociais envolvidas nesse processo. 


\section{Estágio de docência: entre os fios da subjetividade social e da alteridade}

Posteriormente à observação da turma, foi possível verificar como os alunos se relacionavam no ambiente da escola. Com base nesses dados foi elaborado o projeto de intervenção pedagógica, que deu continuidade ao trabalho da professora no $1^{\circ}$ ano, baseado no tema Convivência. O objetivo foi pensar sobre o convívio dentro da escola, considerando os sujeitos e suas subjetividades, a alteridade nas relações sociais e a ocupação do espaço. Com o tema, foi possível trabalhar conteúdos dos componentes curriculares de Português (alfabetização, histórias e processos de comunicação), Geografia e Matemática (cartografia e espaço), Filosofia (valores éticos e morais) e Artes (desenho coletivo).

As situações significativas do processo vivenciado na docência, que serão descritas a seguir, foram aquelas que envolveram o uso da escrita espontânea, nosso objeto de estudo. A descrição considera as relações que os alunos estabeleceram entre si, com os colegas, o docente e os objetos, além das configurações do espaço.

No primeiro dia de docência, os alunos realizaram situações significativas de convivência relacionadas à alteridade. Eles socializaram suas experiências com os colegas de classe durante toda a manhã nas atividades de desenho, diálogo e escrita espontânea. Em uma das primeiras atividades, as crianças receberam um crachá e o customizaram com um desenho que as representasse e colocaram seu nome (Figura 5). Depois disso, formaram duplas e trocaram seus crachás com os dos colegas. Nesse momento, algumas crianças tiveram dificuldade em compartilhar seu crachá, uma das alunas ficou contrariada e não queria ceder seu crachá para o colega da sua dupla. Foi necessário conversar com ela e explicar o objetivo da atividade individualmente.

Figuras 5 - Aluno customizando seu crachá

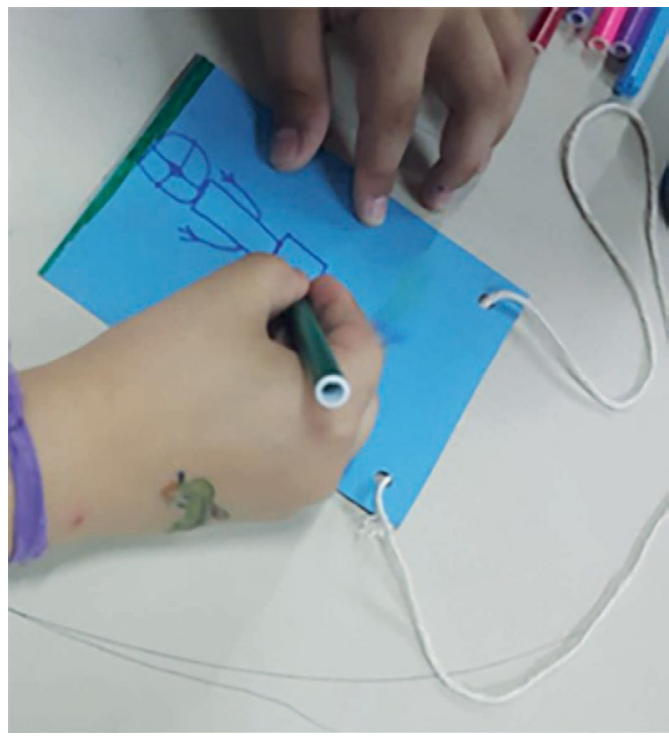

Fonte: foto elaborada para registro de estágio.

Após a troca dos crachás, os alunos deveriam conversar com seus pares e fazer perguntas relacionadas às brincadeiras favoritas, animais prediletos, gostos pessoais, lugares em que gostam de passear e, durante o trabalho, anotar as respostas do colega em uma folha (Figura 6). 
Figura 6 - Situação significativa de escrita espontânea com os colegas

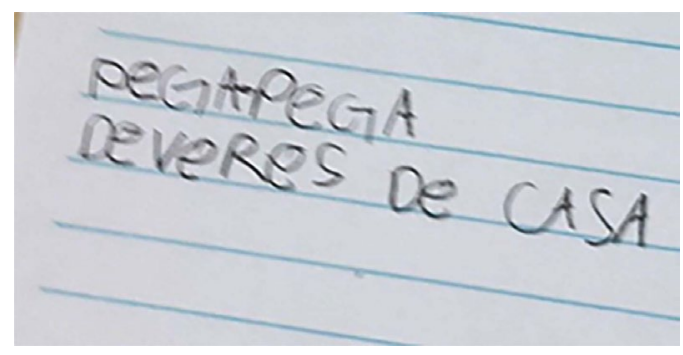

Fonte: foto elaborada para registro de estágio.

Durante essa atividade, o estagiário docente auxiliou as crianças em relação às palavras que elas tinham dúvida para escrever. Em algumas palavras, a turma toda contribuía para sua escrita no quadro, já em outros casos, o estagiário, individualmente, instigava a criança a pensar sobre a grafia da palavra (Figura 7).

Figura 7 - Mediações do estagiário com os alunos

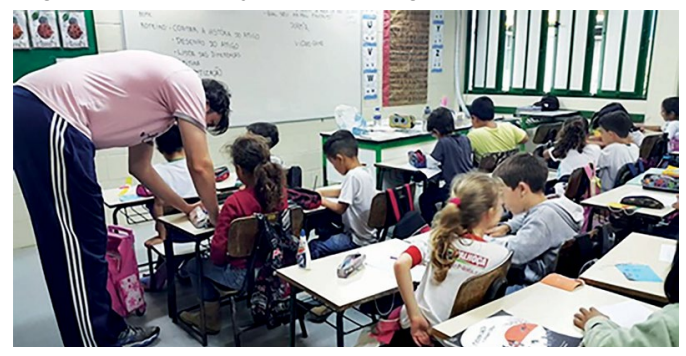

Fonte: foto elaborada para registro de estágio.

Em seguida, as crianças desenharam o colega com base nas conversações realizadas anteriormente. Para isso, precisaram retomar o que haviam escrito sobre o colega para agregar elementos da conversação ao desenho (Figura 8). Vigotski constata que as crianças em idade escolar tem a capacidade:
[...] de mudar de uma escrita puramente pictográfica para uma escrita ideográfica, onde as relações e significados individuais são representados através de sinais simbólicos abstratos (2008, p. 137).

No desenho (Figura 8), é possível observar a representação que a criança fez do colega e um elemento abstrato que ocupa o espaço inferior direito. Ao final da atividade, os alunos foram encorajados a falar para a classe a respeito das diferenças que apresentam em relação a sua dupla, fossem elas comportamentais ou físicas.

Figura 8 - Desenho do colega

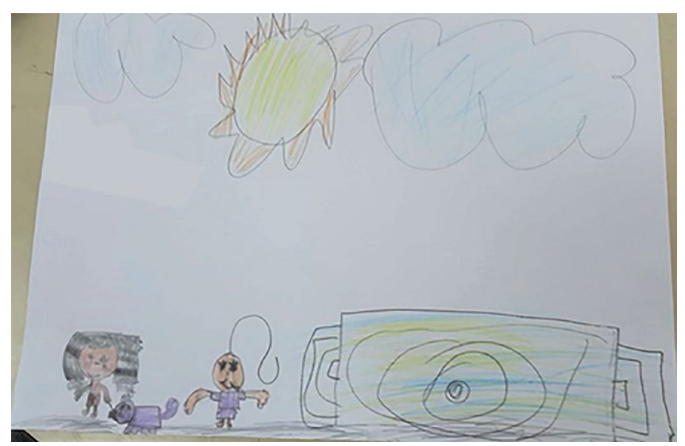

Fonte: foto elaborada para registro de estágio.

No segundo dia de intervenção, os alunos participaram de situações significativas relacionadas à cartografia. Em uma dessas situações, eles desenharam o mapa da escola em planta baixa e identificaram os lugares da escola com seus respectivos nomes. Antes disso, foi feito, em conjunto, um mapa no quadro para ajudar os alunos na compreensão da atividade (Figura 9). O estagiário docente perguntou às crianças quais lugares elas conheciam na escola e então 
fez desenhos no quadro sob a orientação delas. Na medida em que ia desenhando, ele anotava o nome dos lugares. Após o término do modelo de mapa geral da escola, mesmo com a falta de indicação de alguns outros locais, ele foi apagado do quadro. A partir de então, foi explicado às crianças que agora elas iriam desenhar seu próprio mapa da escola em uma folha em branco. Dessa forma, os alunos criaram um mapa que, para eles, representava sua escola, exercitando, com isso, a escrita espontânea, e tendo autonomia para incluir outros locais da escola que não foram comtemplados no primeiro momento.

Figura 9 - Mapa da escola no quadro

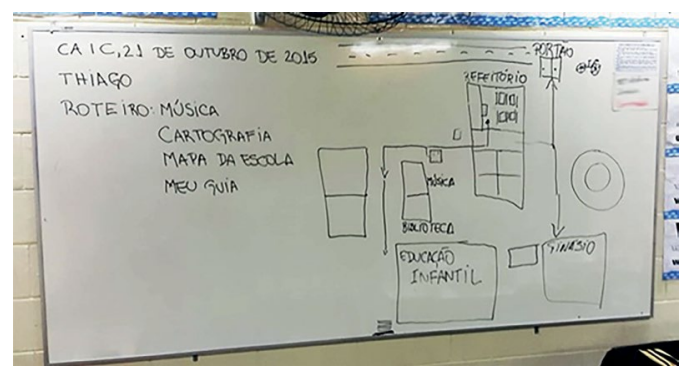

Fonte: foto elaborada para registro de estágio.

Todas as crianças participaram ativamente da prática; algumas tiveram mais facilidade nas representações no desenho e na escrita, outras menos. Permitiu-se que os alunos se ajudassem, de modo que os que tinham mais facilidade na escrita contribuíssem para a descrição dos espaços da escola daqueles que haviam encontrado dificuldade no exercício (Figura 10).
Figura 10 - Alunos ajudando-se durante a realização da situação significativa

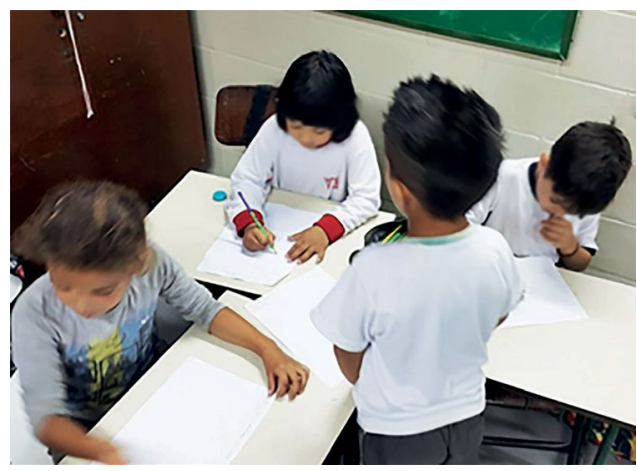

Fonte: foto elaborada para registro de estágio.

Embora tenha sido feito um modelo explicativo do mapa no quadro branco anteriormente, os alunos ficaram receosos em desenhá-lo sem ter alguma referência para a qual pudessem olhar. Nas Figuras 11 e 12, é possível perceber as representações de dois alunos e a escrita dos nomes dos lugares da escola.

Figura 11 - Exemplo de representação da escola por um aluno

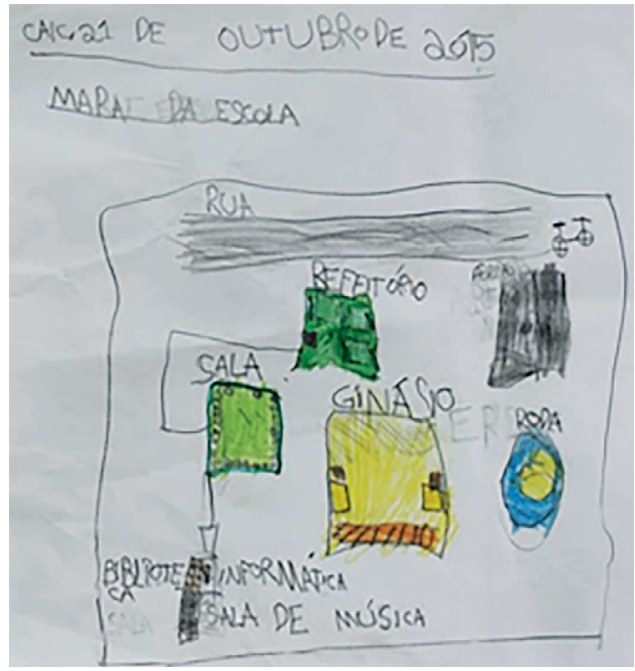

Fonte: foto elaborada para registro de estágio. 
Figura 12 - Exemplo de representação da escola por um aluno

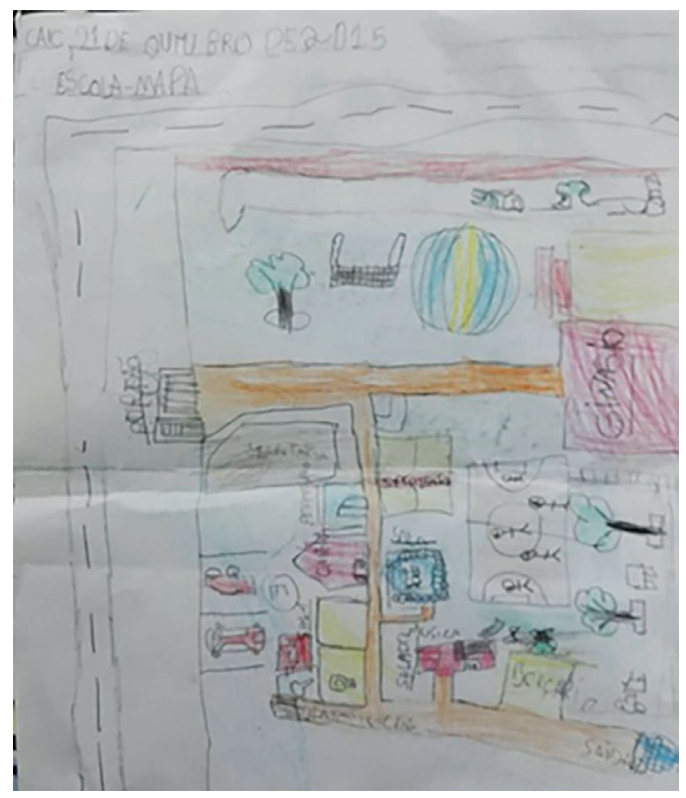

Fonte: foto elaborada para registro de estágio.

Nos momentos em que as crianças tinham dificuldade em escrever alguma palavra, o estagiário docente as auxiliava, indo ao quadro quando era uma dúvida de todos os alunos ou pedindo para algum aluno ajudar seu colega. Com essa atividade, percebe-se que os alunos aprenderam sobre uma forma de representação cartográfica e que foram alfabetizados ao mesmo tempo, ou seja, aconteceu o processo alfabetizar letrando. Segundo Soares,

[...] o ideal seria alfabetizar letrando, ou seja, ensinar a ler e a escrever no contexto das práticas sociais da leitura e da escrita, de modo que o indivíduo se torne, ao mesmo tempo, alfabetizado e letrado (2001, p. 47).
Podemos dizer, então, que por meio dessa atividade o processo de apropriação da leitura e da escrita e de aprendizagem dos conhecimentos foi acontecendo simultaneamente com a mediação pedagógica conduzida pelo professor, pois, assim como Mello e Farias (2010), entendemos que a escola é o lugar da cultura mais elaborada, o lugar de ampliar os repertórios culturais. Dessa maneira, para além das concepções de alfabetização que consideram apenas o ato mecânico dos alunos nos anos iniciais para codificar e decodificar palavras, o processo de alfabetização, nessa experiência de estágio, aconteceu em um espaço em que as crianças entraram no mundo da leitura e da escrita e, ao mesmo tempo, no seu contexto de uso, por meio dos seus gêneros e práticas sociais, tornou-se, dessa forma, um instrumento para auxiliá-las em seu cotidiano, no seu exercício como cidadão.

No terceiro dia de intervenção pedagógica do estágio, foi realizado o momento do mapa corpo, conforme Dal Pont (2015). As crianças tiveram que desenhar e construir/modelar figuras humanas de maneira coletiva e compartilhada, de forma que esses conhecimentos fizessem sentido para elas, sempre em um contexto de letramento. Em um primeiro momento, o professor conversou com os alunos sobre o corpo e suas partes e fez uma lista no quadro. Para compor essa lista, os alunos que sugeriam o nome da parte do corpo iam até o quadro e escreviam a palavra (Figura 13). 
Figura 13 - Lista de palavras de partes do corpo humano no quadro

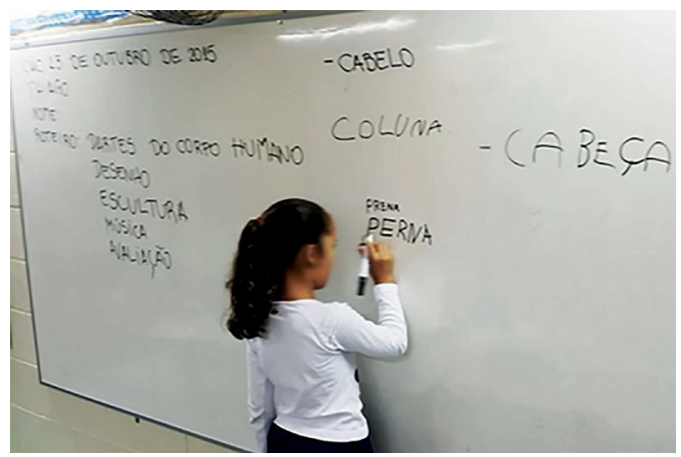

Fonte: foto elaborada para registro de estágio.

Após essa discussão, estagiário e alunos foram até o corredor da escola para o desafio do desenho compartilhado. Verificou-se que as crianças gostaram de sair da sala e fazer essa atividade externa, uma vez que se divertiram, brincaram, riram e se engajaram nos desenhos (Figuras 14 e 15).

Figura 14 - Desenho coletivo no corredor

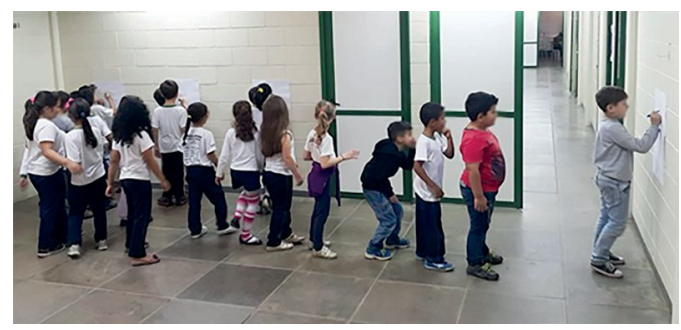

Fonte: foto elaborada para registro de estágio.
Figura 15 - Resultado dos desenhos coletivos de cada equipe

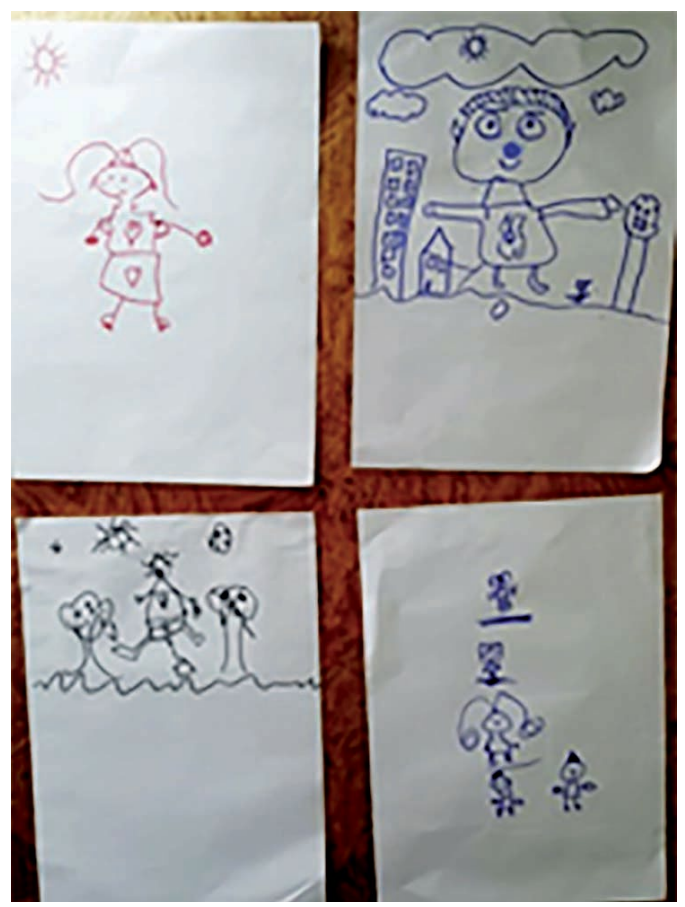

Fonte: foto elaborada para registro de estágio.

O exercício do desenho compõe parte importante da compreensão e do desenvolvimento da escrita. $\mathrm{O}$ desenho coletivo possibilitou aos alunos praticarem a colaboração por meio da continuação do traço de outro colega, e ao final surgiu uma composição visual inusitada, feita por todos. Assim, nota-se que existem diferentes possibilidades pedagógicas nas atividades que envolvem a escrita espontânea, seja na formação do grupo de alunos, nas mediações pedagógicas, seja na exploração dos espaços e tempos escolares, sempre de forma significativa. Dentro da concepção da prática pedagógica apresentada, é possível perceber a 
subjetividade social e a alteridade eminentes durante todo o processo.

\section{Escrita espontânea, subjetividade social e alteridade}

Em decorrência das situações significativas de escrita espontânea propostas na intervenção de estágio, com enfoque na subjetividade social e na alteridade, algumas reflexões podem ser estabelecidas paralelamente ao processo de alfabetização. A Lei no 9.394, de 20 de dezembro de 1996, Lei de Diretrizes e Bases da Educação Nacional (BRASIL, 1996), relata que na formação básica do cidadão no ensino fundamental, que inicia aos seis anos de idade, deve existir a formação de valores e atitudes, o fortalecimento da solidariedade humana e da tolerância recíproca. Já as Diretrizes Curriculares Nacionais Gerais da Educação Básica, em suas disposições gerais, afirmam que é necessário problematizar o desenho da instituição escolar que não tem conseguido responder à singularidade dos sujeitos, e dispõem que:

A relação entre cuidar e educar se concebe mediante internalização consciente de eixos norteadores, que remetem à experiência fundamental do valor, que influencia significativamente a definição da conduta, no percurso cotidiano escolar. Não de um valor pragmático e utilitário de educação, mas do valor intrínseco àquilo que deve caracterizar o comportamento de seres humanos, que respeitam a si mesmos, aos outros, à circunstância social e ao ecossistema. Valor este fundamentado na ética e na estética, que rege a convivência do indivíduo no coletivo, que pressupõe relações de cooperação e solidariedade, de respeito à alteridade e à liberdade (BRASIL, 2013, p. 18).

Os Parâmetros Curriculares Nacionais de Língua Portuguesa (BRASIL, 1997) enfatizam o papel da ação e reflexão do aluno no processo de alfabetização, de modo que seus caminhos percorridos favoreçam a intervenção pedagógica. Conforme o documento, os erros devem se constituir pistas e contribuir para o planejamento da prática pedagógica. Com base nesses documentos, é importante considerar que há questões humanas que envolvem a identidade do aluno e as relações que estabelecem com o ambiente social e que precisam estar atreladas à escola e, consequentemente, no desenvolvimento da linguagem escrita.

Durante o processo de intervenção docente, a escrita espontânea foi mediada pelo estagiário, não sendo, sobremaneira, espontaneísta, mas, sim, relacional. A pedagogia relacional considera que a prática pedagógica é permeada por diferentes sujeitos que interagem no espaço (BARBOSA, 2009). Nesse sentido, no processo pedagógico não há uma relação de hierarquia no processo de ensino e de aprendizagem, nem o aluno é posto como centro do processo ou o docente apresenta uma postura adultocêntrica; esse é um processo de interações, que ora recai sobre o aluno, ora sobre o professor, ora sobre ambos. As relações entre aluno-aluno, docente-aluno e aluno-objeto são consideradas essenciais nessa prática. 
Dessa maneira, o estagiário docente atuou como designer do processo de comunicação nos espaços de trabalho. Ele entrava em contato com os alunos e os estimulava a estabelecer contato com seus colegas durante as situações significativas de alfabetização. Tais ações implicaram, também, que os sujeitos se olhassem, percebessem a sua subjetividade individual e a alteridade do outro. Rosa (2012), ao falar da alteridade como paradigma educativo, cita o filósofo Lévinas, que propõe outra forma de ver a humanidade - o ser humano aberto à alteridade se manifesta no rosto do outro. Atrelado a isso está o que Lévinas compreende sobre a linguagem:

\begin{abstract}
A linguagem não é simplesmente instrumento ou meio para conhecer o outro, nem é experiência. É o "Eis-me aqui!" como resposta ao outro que me convoca pela epifania do seu rosto. A linguagem no sentido proposto por Lévinas, coloca-se na perspectiva da ideia de infinito. $\mathrm{O}$ outro clama a mim por uma resposta. A abertura à palavra do outro faz-me sair do meu mundo, do meu enclausuramento. A linguagem é o espaço de encontro do eu com o outro (1998 apud ROSA, 2012, p. 58).
\end{abstract}

Por consequência, nos momentos em que os colegas ajudavam uns aos outros ou produziam conjuntamente discursos que resultavam do exercício da escrita espontânea, percebia-se, na constituição dessa relação, interações que favoreciam o encontro entre os pares, ou seja: o rosto de cada um em contato com os outros, mediados pelas linguagens, favorecia por meio desse discurso o canal de encontro. Esse encontro é fundamental para criar e ampliar o processo de discursivização entre os sujeitos do ensino e do aprendizado.

Rey (1997) assegura que na formação da personalidade a comunicação é essencial, pois, trata-se de uma ferramenta fundamental para o desenvolvimento do conhecimento e representa um processo necessário para o desenvolvimento pessoal do aluno. Então, à medida que $o$ aluno interage nesse ambiente alfabetizador, ele acaba também contribuindo para desenvolver os outros sujeitos que estão com ele, por meio das relações interpessoais e intersubjetivas. É um processo individual e coletivo. Isso pode ser interligado ao conceito de subjetividade social proposto por Rey:

Entendemos como subjetividad social, precisamente el sistema integral de configuraciones subjetivas (grupales o individuales), que se articulan en los distintos niveles de la vida social, implicándose de forma diferenciada en las distintas instituciones, grupos y formaciones de una sociedad concreta. Estas formas tan disímiles, guardan complejas relaciones entre si y con el sistema de determinantes de cada sociedad concreta, aspectos que deben ser integrados y explicados por la psicología social (1993, p. 31).

$\mathrm{O}$ autor aplica esse conceito na instituição escolar e afirma que todo tipo de padrão estandardizado de unidade do grupo que impõe regras rígidas destinadas a eliminar as diferenças individuais e desconsiderar o aluno como sujeito do desenvolvimento precisa ser quebrado (REY, 1997). Os alunos que, durante o período de observação, por vezes levaram muito tempo para desenvolver sua escrita e se atrasaram no decorrer das 
demais atividades, tiveram, no período de intervenção, seu tempo respeitado, e contaram com a ajuda do estagiário docente e de colegas de turma para buscar compreender o que estavam fazendo e prosseguir nas atividades seguintes. Eles foram encorajados a falar de suas diferenças nas atividades de escrita espontânea e a valorizar as escolhas e tempos dos demais colegas.

Nas mediações, o estagiário docente também valorizou os momentos de atendimento individual, em pequenos e grandes grupos, de modo a ofertar possibilidades variadas de relações entre os pares. O espaço físico também mudava de acordo com as atividades, era dinâmico, e as carteiras eram estruturadas de acordo com a formação do grupo de trabalho de cada dia ou conforme as mediações que seriam estabelecidas com o estagiário docente.

Vale ressaltar que o espaço também constitui os sentidos que são construídos nas relações interativas do processo de ensino e de aprendizagem, que são tão importantes quanto todas as outras dimensões do processo. De acordo com Viñao Frago e Escolano:

[...] a arquitetura escolar é [...] por si mesma um programa, uma espécie de discurso que institui na sua materialidade um sistema de valores, como os de ordem, disciplina e vigilância, marcos para a aprendizagem sensorial e motora e toda uma semiologia que cobre diferentes símbolos estéticos, culturais e também ideológicos. [Neste sentido] o espaço escolar tem de ser analisado como um constructo cultural que expressa e reflete, para além de sua materialidade, determinados discursos (1998, p. 26).
Mediante essas reflexões, podemos dizer que, para além da sala de aula, outros espaços também constituem e dão sentido para a relação pedagógica. Nessa experiência, o corredor também foi utilizado como espaço de aprendizagem do processo de apropriação da linguagem escrita. Ao final do estágio, a professora titular da turma entusiasmou-se e tomou a experiência vivenciada como referência de boa prática e resolveu acrescentar novos conhecimentos ao seu trabalho pedagógico.

\section{Considerações finais: produzindo um efeito de fecho}

O estágio supervisionado no ciclo de alfabetização propôs ações de trabalho com a turma do $1^{\circ}$ ano do ensino fundamental que modificassem as formas de organização dos alunos (individualmente, em pequeno e grande grupo), os tempos e os espaços, resultando em novas interações entre alunos, professor-aluno, alunos-objetos.

O objetivo deste artigo foi apresentar metodologicamente a escrita espontânea em uma turma de alfabetização como prática de trabalho da subjetividade social e da alteridade dos alunos na ampliação dos seus repertórios culturais no processo de apropriação da linguagem escrita, no lugar social que é a escola.

Nas situações significativas de aprendizado, foram propostas relações de colaboração e cooperação entre os pares. 
Nessas interações, os alunos brincaram, riram, desenharam, escreveram e se expressaram. O processo de alfabetização e o letramento permearam todas as atividades desenvolvidas no estágio. Os alunos, em conjunto com o estagiário (professor e um dos autores deste texto) e a professora da turma e supervisora do estágio, escreveram seus nomes e os nomes dos colegas, tiveram a oportunidade de estar em contato com diferentes fonemas e grafemas, de ampliar seus conhecimentos sobre a escrita, ao mesmo tempo em que eram estimulados a escrever de acordo com o que já dominavam em relação ao aprendizado da escrita. Esse processo mediado pela ação docente foi planejado tendo a noção de texto/gêneros discursivos/práticas discursivas como eixo norteador das ações pedagógicas, criando para os alunos a oportunidade de interpretar e de se expressar por meio de diferentes linguagens verbais (listas, diálogo, entrevistas) e não verbais (desenhos e mapas).

De acordo com Mendonça (2007), a escola entendida no contexto sociocultural deve ampliar as experiências de letramento das crianças para a formação de sujeitos amplamente letrados, de modo que eles possam ter mais autonomia e segurança e diversas práticas de letramento.

O desenvolvimento dessa experiência possibilitou aos alunos o diálogo e a escuta dos colegas, de modo a conhecer melhor o outro, por meio de narrativas orais e escritas; eles aprenderam sobre as diferenças baseando-se na percepção dos sujeitos na sala de aula e no trabalho sobre convivência; eles escreveram e leram por meio de atividades de alfabetização e letramento, contextualizadas e espontâneas; eles produziram interações propositivas de leitura, construção e pensamento do espaço físico e social da escola, a partir da cartografia do território, com a elaboração de mapas e com o olhar sensível sobre a escola, e vivenciaram situações de desafios comunicacionais, de forma a negociar e tomar decisões acerca de tarefas coletivas.

Outro ponto importante a destacar é que houve ponderação durante a realização das atividades desenvolvidas no estágio em relação ao tempo das crianças, de modo que as atividades escolares não as obrigassem a uma rotinização cronometrada. Na medida em que foi sendo observado o crescente interesse e engajamento dos alunos por determinada atividade, essa situação era aproveitada para aprofundar seus conhecimentos, sempre permeada pela concepção de alfabetização e letramento de forma indissociável.

É possível perceber, então, que a escrita espontânea pode ser utilizada no processo de alfabetização como uma prática que se constitui também pela subjetividade e alteridade dos sujeitos envolvidos. Nesse sentido, reconhecer o conceito de subjetividade e de alteridade implicados na relação entre os sujeitos que fazem parte desse processo contribui para compreender os sentidos que se 
constituem nessa relação que envolve a escrita espontânea no processo inicial de alfabetização e letramento.

Essas são reflexões que não se esgotam. Refletir sobre essa experiência nos levou a ampliar nossos conhecimentos sobre o quanto a subjetividade e a alteridade estão materializadas na relação pedagógica, assim como perceber como essas práticas constituem os sujeitos que vivem cotidianamente o processo de ensinar e aprender na escola, e o quanto precisamos considerar essas dimensões no processo de apropriação da linguagem escrita, nesse caso, no processo de desenvolvimento/de vivência da escrita espontânea pelos aprendizes da escrita e da leitura.

\section{Otherness and social} subjectivity through spontaneous writing in literacy cycle: experience report in elementary school

\begin{abstract}
This is an experience report of the supervised Internship Experience in the Literacy Cycle in the Pedagogy course that took place in the Center of Integral Attention to Children Prof. Febrônio Tancredo Oliveira, in Palhoça, SC. The objective of the stu$\mathrm{dy}$ is methodologically present spontaneous writing in a literacy class as a working practice of social subjectivity and otherness. The group consisted of 23 students who participated in the classes between August and October 2015. We used the following data col-
\end{abstract}

lection techniques: internship diary, participant observation, photographs, videos and materials produced during the process of observation and intervention. It could be observed that the spontaneous writing in designing relational pedagogy with cultural-historical approach in the literacy process is a practice that is also the social subjectivity (REY, 1993, 1997) and otherness as an educational paradigm (ROSA, 2012).

Keywords: Otherness. Social subjectivity. Literacy. Spontaneous writing. Elementary school.

\section{Notas}

1 A partir da Lei $\mathrm{n}^{\circ} 11.274$ (BRASIL, 2006), o ensino fundamental passou a ter nove anos de duração, e os três primeiros anos do ensino fundamental/anos iniciais passaram a compor o chamado ciclo de alfabetização.

2 Os diferentes níveis de apropriação da linguagem escrita foram analisados, neste texto, com base nos estudos de Ferreiro e Teberosky (1999). Vale ressaltar que, embora tenhamos a clareza de que as teorias que embasam os estudos desses autores, do ponto de vista epistemológico, são antagônicas em relação às teorias que subsidiam os estudos realizados a partir da teoria histórico-cultural, entende-se que as duas bases têm contribuições importantes no que tange à escrita espontânea, nosso objeto de estudo, e não interferem no nosso foco, pois a reflexão central versa sobre a alteridade e a subjetividade, e as respectivas bases conceituais não geram impacto sobre as reflexões. 


\section{Referências}

AUTHIER-REVUZ, Jacquelin. Heterogeneidade(s) enunciativa(s). Cadernos de Estudos Linguisticos, Campinas: IEL, n. 19, p. 25-42, 1990.

BARBOSA, Maria Carmen Silveira. Práticas cotidianas na educação infantil: bases para a reflexão sobre as orientações curriculares. Brasília: MEC, 2009. Disponível em: $<$ http://portal.mec.gov.br/dmdocuments/ relat_seb_praticas_cotidianas.pdf $>$. Acesso em: 7 mar. 2016.

BRASIL. Diretrizes Curriculares Nacionais Gerais da Educação Básica. Brasília: MEC, SEB, DICEI, 2013. Disponível em: <http:// portal.mec.gov.br/index.php?option=com docman\&view=download\&alias $=15548-d-c-n-$ -educacao-basica-nova-pdf\&Itemid=30192>. Acesso em: 7 mar. 2016.

Lei $\mathrm{n}^{-}$9.394, de 20 de dezembro de 1996. Estabelece as diretrizes e bases da educação nacional. Brasília, DF, 1996. Disponível em: <http://www.planalto.gov. br/ccivil_03/Leis/L9394.htm>. Acesso em: 7 mar. 2016.

. Parâmetros Curriculares Nacionais: Língua Portuguesa. Brasília: SEB, 1997. Disponível em: <http://portal.mec.gov.br/ seb/arquivos/pdf/livro02.pdf>. Acesso em: 8 mar. 2016.

Lei $\mathrm{n}^{\circ} 11.274$, de 6 de fevereiro de 2006. Altera a redação dos artigos $29,30,32$ e 87 da Lei no. 9394, de 20 de dezembro de 1996, que estabelece as diretrizes e bases da educação nacional, dispondo sobre a duração de 9 (nove) anos para o ensino fundamental, com matrícula obrigatória a partir dos 6 (seis) anos de idade. Brasília, DF, 2006. Disponível em: <http://www.planalto.gov. br/ccivil_03/_ato2004-2006/2006/lei/111274. htm>. Acessos em: 13 jul. 2016.

DAL PONT, Karina Rousseng. Fundamentos e metodologia de geografia para os anos ini- ciais do ensino fundamental: livro didático. Palhoça: UnisulVirtual, 2015.

FERREIRO, Emília; TEBEROSKY, Ana. Psicogênese da língua escrita. Porto Alegre: Artes Médicas Sul, 1999.

FREIRE, Paulo. Extensão ou comunicação? 17. ed. São Paulo: Paz e Terra, 2015.

. Pedagogia da autonomia: saberes necessários à prática educativa. São Paulo: Paz e Terra, 1996.

GOULART, Cecília. A organização do trabalho pedagógico: alfabetização e letramento como eixos orientadores. In: BEAUCHAMP, Jeanete; PAGEL Sandra Denise; NASCIMENTO, Aricélia Ribeiro do (Org.). Ensino fundamental de nove anos: orientações para a inclusão da criança de seis anos de idade. Brasília: Ministério da Educação, Secretaria de Educação Básica, 2007. p. 85-96.

KRAMER, Sônia. A infância e sua singularidade. In: BEAUCHAMP, Jeanete; PAGEL Sandra Denise; NASCIMENTO, Aricélia Ribeiro do (Org.). Ensino fundamental de nove anos: orientações para a inclusão da criança de seis anos de idade. Brasília: Ministério da Educação, Secretaria de Educação Básica, 2007. p. 13-23.

MELLO, Suely Amaral; FARIAS, Maria Auxiliadora. A escola como lugar da cultura mais elaborada. Educação, Santa Maria, v. 35 , n. 1, p. 53-68, jan./abr. 2010. Disponível em: <http://cascavel.ufsm.br/revistas/ ojs-2.2.2/index.php/reveducacao/article/ view/1603/898>. Acesso em: 7 mar. 2016.

MENDONÇA, Márcia. Gêneros: por onde anda o letramento? In: SANTOS, Carmi Ferraz; MENDONÇA, Márcia. Alfabetização e letramento: conceitos e relações. Belo Horizonte: Autêntica, 2007. p. 37-56.

MOÇO, Anderson. Diagnóstico na alfabetização para conhecer a nova turma. Revista Nova Escola, São Paulo, mar. 2009. Disponível em: <http://revistaescola.abril.com. br/lingua-portuguesa/alfabetizacao-inicial/ 
conhecer-nova-turma-431205.shtml>. Acesso em: 14 fev. 2016.

ORLANDI, Eni Puccinelli. A linguagem e seu funcionamento: as formas do discurso. 6. ed. Campinas: Pontes, 2011.

PFEIFFER, Cláudia C. Compreender discursivamente a escola: uma possibilidade construída. In: RODRIGUES, Eduardo Alves; SANTOS, Gabriel Leopoldino dos; CASTELO BRANCO, Luzia Katia Andrade (Org.). Análise de discurso no Brasil: pensando o impensado sempre. Uma homenagem a Eni Orlandi. Campinas: Editora RG, 2011. p. 231-258.

REY, Fernando Luis González. La subjetividad social y su expresión en la enseñanza. Temas em Psicologia, Ribeirão Preto, v. 5, n. 3, p. 95-107, dez. 1997. Disponível em: <http:// pepsic.bvsalud.org/scielo.php?script $=$ sci arttext\&pid=S1413-389X1997000300008\& lng=pt\&nrm=iso $>$. Acesso em: 8 mar. 2016.

. Problemas epistemológicos de la psicología. México: Colegio de Ciencias y Humanidades de la Universidad Nacional Autónoma de México, 1993.

ROSA, Luís Carlos Dalla. Educar para a sabedoria do amor: a alteridade como paradigma educativo. São Paulo: Paulinas, 2012.

SILVA, Ademar da. Alfabetização: a escrita espontânea. São Paulo: Contexto, 1991.

SOARES, Magda. Alfabetização e letramento. 6. ed. São Paulo: Contexto, 2011.

. Letramento: um tema em três gêneros. 2. ed. Belo Horizonte: Autêntica, 2001.

VIGOTSKI, Lev Semenovich. A pré-história da linguagem escrita. In: VIGOTSKI, L. S. A formação social da mente: desenvolvimento dos processos psicológicos superiores. 7. ed. São Paulo: Martins Fontes, 2008. p. 125-145.

VIGOTSKII, Lev Semenovich. Aprendizagem e desenvolvimento intelectual na idade escolar. In: VIGOTSKII, Lev Semenovich; LURIA, Alexander Romanovich; LEONTIEV,
Alex N. Linguagem, desenvolvimento e aprendizagem. São Paulo: Ícone, 1988. p. 103-117.

VIÑAO FRAGO, Antônio; ESCOLANO, Agustin. Currículo, espaço e subjetividade: a arquitetura como programa. Trad. Alfredo Veiga-Neto. Rio de Janeiro: DP\&A, 1998.

WEISZ, Telma. $O$ diálogo entre o ensino e a aprendizagem. 2. ed. São Paulo: Ática, 2006. 